\title{
ESTUDO DA ADEQUAÇÃO DO USO DO SOLO, NO MUNICÍPIO DE MARINGÁ - PR, UTILIZANDO-SE DE GEOPROCESSAMENTO
}

\section{ZACARIAS X. BARROS ${ }^{1}$, MARISA T. TORNERO ${ }^{2}$, NILZA A. F. STIPP ${ }^{3}$, LINCOLN G. CARDOSO ${ }^{1}$, RONALDO A. POLLO ${ }^{2}$}

\begin{abstract}
RESUMO: O presente trabalho tem por finalidade o estudo da adequação do uso do solo e análise da carta de aptidão agrícola, bem como o mapeamento da ocupação do solo, por meio da criação e estruturação de um banco de dados utilizando-se de Geoprocessamento, visando a atualizações e interações das informações com rapidez e eficiência, permitindo adaptações e/ou confecções de mapas temáticos da área estudada. Por meio da análise conjunta dos mapas de ocupação do solo com a carta de aptidão agrícola, pode-se constatar que: o município de Maringá - PR, apresenta ocupação de suas terras, em sua grande maioria, em acordo com a aptidão agrícola recomendada para a região; a alta porcentagem de mata nativa em terras de boa aptidão para culturas, certamente está vinculada a obediência às leis ambientais em vigor.
\end{abstract}

PALAVRAS-CHAVE: aptidão agrícola, ocupação do solo, SIG.

\section{STUDY OF THE ADAPTATION OF THE SOIL USE IN MARINGÁ COUNTY, PARANÁ STATE, BRAZIL, USING GEOPROCESSING}

SUMMARY: The present work had the objective of studying the adaptation of the soil and analyzing the agricultural suitability map, as well as the mapping of the occupation of the soil, by creating and structuring a database using Geoprocessing. The research aimed updates and iterations of the information quickly and efficiency, allowing adaptations and/or elaboration of thematic maps of the studied area. By the occupation maps of the soil with the agricultural suitability map, it could be verified that: the County Maringá - PR, has the occupation land in agreement with agricultural suitability that is recommended for the region; the high percentage of native woods in good suitability soil for cultures, it is in according to environmental laws.

KEYWORDS: land evaluate system, soil occupation, GIS.

\section{INTRODUÇÃO}

Na década de 1970, surgiram os primeiros sinais de degradação ambiental ocasionados pelo modelo de crescimento econômico desencadeado no Brasil a partir de 1940, com a incorporação dos padrões tecnológicos multinacionais pela indústria, mas inadequados à preservação do meio ambiente.

Esse processo de industrialização também ocasionou o início da concentração demográfica nas cidades, culminando com a metropolização dos maiores centros urbanos. A falta de planejamento no uso e ocupação dos espaços geográficos e de investimentos em equipamentos e serviços para o atendimento das necessidades criadas por essa população, certamente, induziu o desequilíbrio do meio ambiente verificado no final do segundo milênio.

Segundo SERRA (1987), o desenvolvimento da indústria a partir da segunda metade do século XVIII, e mais acentuadamente no século XIX, ocasionou a aceleração da urbanização conhecida até

\footnotetext{
${ }^{1}$ Prof. Titular, Departamento de Engenharia Rural, FCA/UNESP, Botucatu - SP, e-mail: labaero@ @fca.unesp.br

${ }^{2}$ Licenciado em Geografia, Departamento de Engenharia Rural, FCA/UNESP, Botucatu - SP.

${ }^{3}$ Profa. Dra., Departamento de Geociências, Universidade Estadual de Londrina, Londrina - PR.

Recebido pelo Conselho Editorial em: 6-12-2002

Aprovado pelo Conselho Editorial em: 28-4-2004
} 
essa época. Em 1800, apenas 2,4\% da população da Terra habitava em cidades com até 20.000 habitantes. Em 1990, porém, cerca de 50\% da população mundial já vivia em cidades com $100.000 \mathrm{ou}$ mais habitantes. Ainda de acordo com o autor, a concentração populacional e a formação de grandes cidades marcam de forma profunda esse processo de industrialização, tornando-se necessário um planejamento integrado de uso e ocupação do solo, com a caracterização de áreas mais propícias para o desenvolvimento ordenado das atividades econômicas, respeitados sempre os ecossistemas da região.

MAGUIRRE et al. (1991) classificam as aplicações dos SIGs em: a) socioeconômicas, envolvendo o uso da terra, seres humanos e a infra-estrutura existente; b) ambientais, enfocando o meio ambiente e o uso de recursos naturais, e c) de gerenciamento, envolvendo administrações públicas, regionais e nacionais, tanto para a definição de novas políticas de planejamento quanto para a avaliação de decisões tomadas.

GOES (1994) define planejamento territorial como um conjunto de posturas e ações políticas de base científica e/ou administrativa, aplicado numa determinada área, com fins de definir normas racionais de uso do meio ambiente e manter o equilíbrio ambiental. Ainda segundo o autor, nesse planejamento, são executadas análises de situações reais, ou seja, inventários, avaliações, monitorias, entre outros.

Segundo RAMALHO FILHO et al. (1994), a aptidão das terras é definida por meio da comparação de suas condições agrícolas com níveis estipulados para cada classe, ou seja, deficiência de fertilidade, deficiência de água, suscetibilidade e impedimentos à mecanização.

O presente trabalho trata de uma pesquisa dirigida a estudos ambientais, utilizando-se de geoprocessamento, com vistas a fornecer subsídios básicos para o planejamento territorial, visando à melhor adequação do uso da terra, por meio da comparação de Cartas de Ocupação do Solo à Carta de Aptidão Agrícola do Município de Maringá - PR, por meio da criação e estruturação de um banco de dados, utilizando-se do geoprocessamento.

\section{MATERIAL E MÉTODOS}

O município de Maringá (Figura 1), com uma área de 489,76 km², localiza-se na região Sul do Brasil, ao Norte do Estado do Paraná, entre as coordenadas $23^{\circ} 15^{\prime} 15^{\prime \prime}$ e $23^{\circ} 33^{\prime} 27^{\prime \prime}$ de latitude sul e $51^{\circ} 50^{\prime} 05^{\prime \prime}$ e $52^{\circ} 05^{\prime} 59^{\prime \prime}$ de longitude oeste. Caracteriza-se por pertencer à área de abrangência dos basaltos originados por derrames basálticos da Formação Serra Geral, pertencente ao Grupo São Bento, capeados a oeste pelos arenitos da Formação Caiuá, Grupo Bauru.

O relevo da região é predominantemente suave ondulado, sobretudo na área de ocorrência do Arenito Caiuá, com altitudes variando entre 500 e 600 m e padrão de drenagem dendrítico, com orientação estrutural caracterizada $(\mathrm{N}-\mathrm{S})$ dos cursos d'água principais e $(\mathrm{E}-\mathrm{W})$ dos seus afluentes.

De acordo com o levantamento de reconhecimento dos solos do Paraná (EMBRAPA, 1984), na área de estudo, encontram-se as seguintes unidades: solos de origem eruptiva (Terra Roxa Estruturada e Latossolo Roxo) e solos resultantes da decomposição do Arenito Caiuá e das rochas eruptivas (Latossolo Vermelho-Escuro e Solos Litólicos).

O tipo climático predominante na região, segundo a classificação de Köeppen é o Cfa, ou seja, subtropical úmido, em que a temperatura média do mês mais frio é inferior a $18{ }^{\circ} \mathrm{C}$, e as temperaturas médias anuais são superiores a $20{ }^{\circ} \mathrm{C}$. 

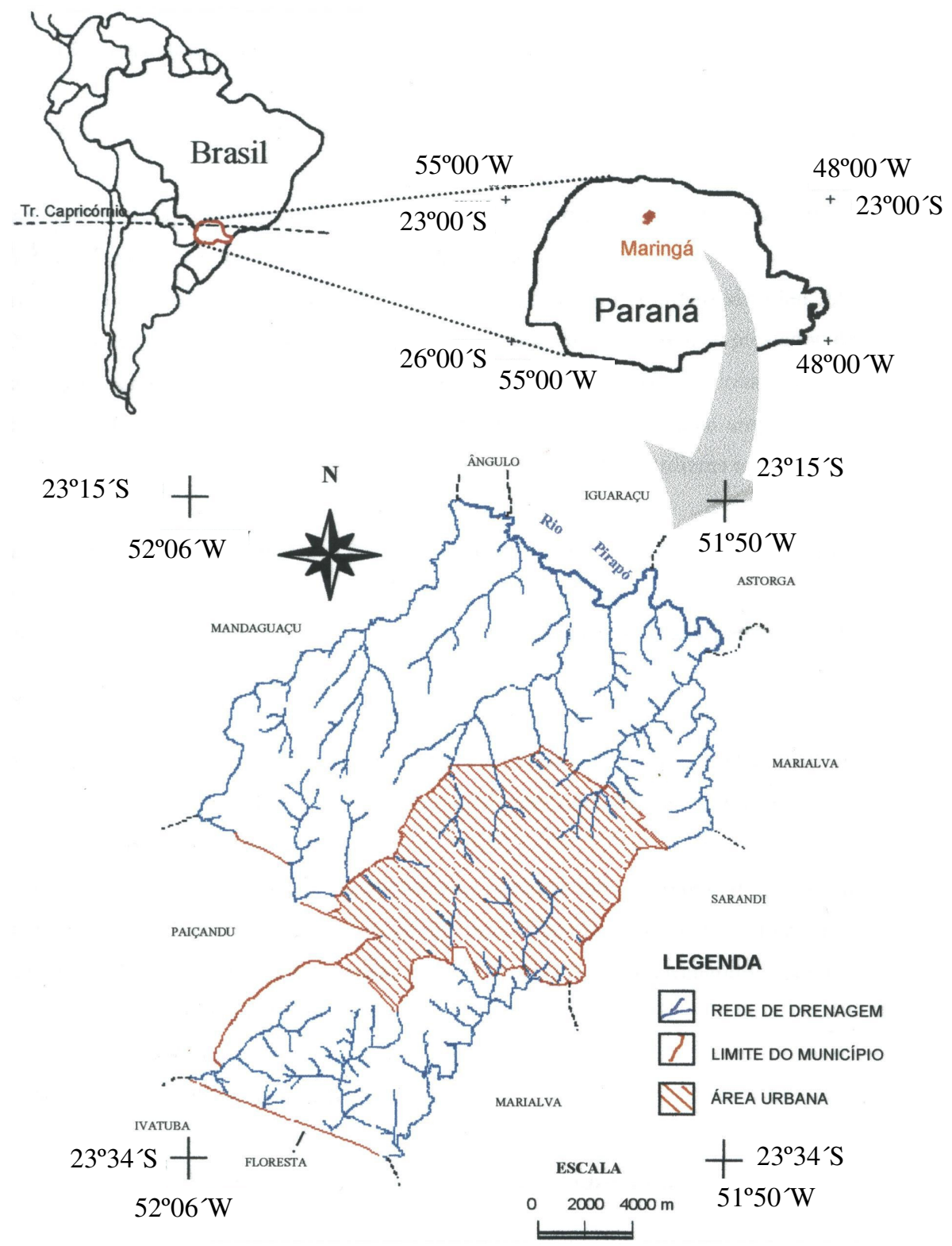

FIGURA 1. Localização do município de Maringá - PR.

Foram utilizadas cartas topográficas do Instituto Brasileiro de Geografia e Estatística (IBGE), editadas em 1972, na escala 1:50.000, pertencentes ao Município de Maringá (Folha de Mandaguaçu SF-22-Y-D-I-4; Folha de Ivatuva SF-22-Y-D-IV-2; Folha de Maringá SF-22-Y-D-II-3 e Folha de Bom Sucesso SF-22-Y-D-V-1), que serviram de base na definição dos limites da área de estudo, extração da rede de drenagem, bem como na aquisição de pontos de controle para o georreferenciamento da imagem digital e carta planialtimétrica na escala 1:20.000, com curvas de nível eqüidistantes em $5 \mathrm{~m}$.

Para a obtenção do mapa de ocupação do solo, bem como para a delimitação da área urbana do Município de Maringá, utilizou-se imagem orbital no formato digital proveniente do satélite LANDSAT-5 sensor TM, em mídia eletrônica (CD-Rom), referente à órbita 223, ponto 76, quadrante B, bandas TM3, TM4 e TM5, de 14-9-1996.

Foi utilizado o software de informações geográficas (SIG)-INPE na geração e tratamento do banco de dados digital. 
$\mathrm{Na}$ classificação da imagem, para a obtenção do mapa de ocupação do solo, foi utilizado o Sistema de Tratamento de Imagens Multiespectrais (SITIM), desenvolvido pelo Instituto Nacional de Pesquisas Espaciais (INPE), versão 2.5, para Sistema DOS.

Os dados foram processados em computador IBM PC/AT - PENTIUM $100 \mathrm{MHz}$, memória de $32 \mathrm{Mb}$ RAM e digitalizados via mesa digitalizadora marca DIGIGRAF, modelo Van Gogh, formato $\mathrm{A}_{0}$ e os mapas finais impressos em HP Deskjet 680C colorida.

A delimitação da área de estudo foi efetuada tendo por base os limites intermunicipais, estabelecidos a partir das cartas topográficas do IBGE, escala 1: 50.000, para o município de Maringá.

Esses limites foram digitalizados via mesa digitalizadora, através do módulo Entrada de Áreas, função Digitalização/Edição.

O pré-processamento, visando a obter uma precisão cartográfica quanto ao posicionamento dos objetos na imagem digital, fez-se por meio da correção geométrica. Essa correção foi obtida por meio do registro da imagem, mediante a aquisição de pontos de controle imagem x mapa, tendo como sistema de referência as cartas topográficas do IBGE (1972).

Após a calibração da mesa, foram escolhidos um total de 40 pontos, de forma que cada um deles fosse facilmente identificado, tanto na imagem digital como nas cartas topográficas, sendo alguns cuidados tomados durante esse procedimento, seguindo as recomendações da ENGESPAÇO (1989).

Esses pontos de controle, indicados na carta topográfica via mesa digitalizadora, foram transferidos, por meio do software SITIM (módulo registro de imagens, função aquisição de pontos de Controle I x M) para a imagem digital, criando uma matriz de reamostragem com as novas coordenadas calculadas. Esse processo é iterativo, de forma que, conforme a precisão do registro alcançada, novos pontos de controle foram utilizados, totalizando os 40 pontos.

Para a classificação digital da imagem, inicialmente, fez-se a interpretação visual utilizando a chave de interpretação de imagens orbitais, que consistiu no reconhecimento de objetos presentes na imagem os quais serviram de amostras de treinamento que, segundo CRÓSTA (1992), essas áreas podem ser usadas como um padrão de comparação, com o qual todos os pixels desconhecidos da imagem serão comparados para decidir a qual classe pertencem. Para a tomada de decisão, foi escolhida a classificação por máxima verosimilhança (ENGESPAÇO, 1989; ALVES et al., 1993; LAPOLLI et al., 1993).

Uma vez coletadas, as amostras foram analisadas quanto ao desempenho médio, abstenção média e confusão média dos temas selecionados.

Os valores das áreas $\left(\mathrm{km}^{2}\right)$ e porcentagem foram determinados pelo SGI, por meio do módulo Manipulação, função calcular áreas de classes.

O mapa de aptidão agrícola teve como base cartográfica as cartas do IBGE (SF-22-Y-D-I-4; SF22-Y-D-IV-2; SF-22-Y-D-II-3 e SF-22-Y-D-VI). Esses limites foram digitalizados via mesa, e, depois, verificaram-se os erros de entrada por meio do ajuste automático e/ou manual das linhas quando necessário.

Para efetivar a definição do projeto, foram informados a projeção cartográfica, o tipo de coordenadas e a escala. Por compreender dados diferentes, visando a sobrepor as informações, cada tema de interesse foi organizado dentro de um plano de informação (PI) independente, como limite do município, rede de drenagem, solo, aptidão agrícola, geologia e curvas de nível. 


\section{RESULTADOS E DISCUSSÃO}

Com o auxílio do Sistema de Tratamento de Imagens Multiespectrais (SITIM), mediante processo iterativo (usuário x programa) de análise e interpretação da imagem digital, foi possível elaborar o mapa de ocupação do solo para o município de Maringá - PR (Figura 2), obtendo-se as seguintes categorias de ocupação: cultura, pastagem, mata nativa, cana-de-açúcar, capoeira, área urbanizada e outros.

$\mathrm{Na}$ Tabela 1, apresentam-se as ocorrências em área $\left(\mathrm{km}^{2}\right)$ e porcentagem $(\%)$ das ocupações do solo no município de Maringá - PR.

Nota-se que a maior ocupação do solo (Tabela 1 e Figura 2) encontrada no município pertence à categoria denominada culturas (basicamente soja/trigo), com 38,95\% da área. Nessa categoria, também foram incluídas as áreas com solo exposto, que reconhecidamente estariam sendo destinadas à cultura de soja, pois a disponibilidade térmica para essa cultura no Paraná exige que a semeadura seja efetuada de 15 de outubro a 15 de dezembro (QUEIRÓZ \& TORRES, 1978) e vale salientar que a imagem utilizada na classificação corresponde ao dia 14 de setembro.

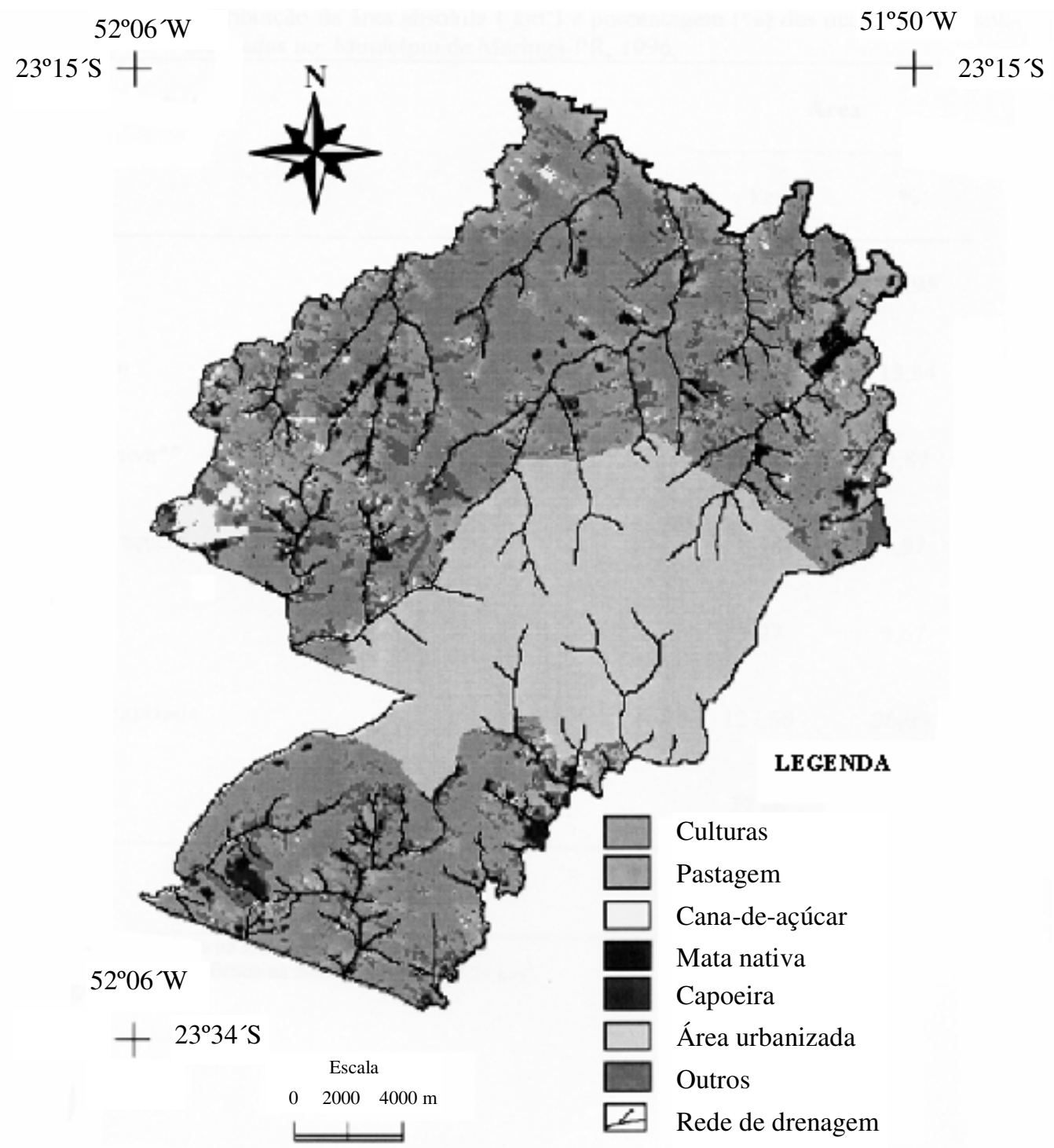

FIGURA 2. Carta de ocupação do solo do município de Maringá - PR, obtida pelo sistema SITIM/INPE. 
As áreas de cultivo que foram observadas na imagem, provavelmente, são de milho, uma vez que, considerando a data da imagem utilizada na classificação (14-09), a soja, bem como o trigo já haviam sido colhidos, cujas colheitas ocorrem de março a abril e no máximo em agosto, respectivamente.

A área urbanizada, ocupando a segunda maior porção do município, $127,58 \mathrm{~km}^{2}$ (26,05\%), conforme Tabela 1, faz divisa a sudoeste com Paiçandu e a leste com Sarandi, o que restringe seu crescimento nessas direções.

TABELA 1. Distribuição da área absoluta $\left(\mathrm{km}^{2}\right)$ e porcentagem $(\%)$ das ocupações do solo mapeadas no município de Maringá - PR, 1996.

\begin{tabular}{lrr}
\hline \multirow{2}{*}{ Ocupações do Solo } & \multicolumn{2}{c}{ Área } \\
\cline { 2 - 3 } & \multicolumn{1}{c}{$\mathrm{km}^{2}$} & 38,95 \\
Cultura* & 190,75 & 13,94 \\
Pastagem & 68,27 & 2,87 \\
Mata nativa** & 14,05 & 1,67 \\
Cana-de-açúcar & 8,18 & 0,67 \\
Capoeira & 3,27 & 26,05 \\
Área urbanizada & 127,58 & 15,85 \\
Outros & 77,66 & 100,00 \\
\hline Total & 489,76 & \\
\hline
\end{tabular}

* Cultura identificada na área urbana foi de $34,18 \mathrm{~km}^{2}$.

** Mata nativa identificada na área urbana foi de $5,31 \mathrm{~km}^{2}$.

A categoria Outros (Figura 2) ocorre disseminada em toda a extensão do município, intercalada pelas demais categorias de ocupação do solo, perfazendo 77,66 km² (Tabela 1) e engloba na sua maior parte múltiplos usos da terra, com predomínio de culturas temporárias: algodão, alho, arroz, feijão, mandioca e milho. Essas culturas foram incluídas numa mesma categoria por ocuparem cada uma delas pequenas áreas dispersas, dificultando, assim, a discriminação dos alvos.

As áreas ocupadas por pastagem perfazem $68,27 \mathrm{~km}^{2}(13,94 \%)$ da área do município de Maringá (Tabela 1), estando localizadas e agrupadas geralmente próximas aos cursos d'água. As maiores concentrações ocorrem a leste e a oeste do município (Figura 2).

A mata nativa ocupa $14,05 \mathrm{~km}^{2}$ da área rural do município (Tabela 1). Apresenta-se, em grande parte, restrita a raras cabeceiras da rede de drenagem, não existindo uma continuidade da vegetação ao longo da drenagem. Apenas duas manchas maiores de vegetação nativa ocorrem nessa área (nordeste e sudeste).

Grande parte da vegetação encontrada na área urbana localiza-se em reservas florestais com matas naturais e parques municipais.

Considerando que 2,34 $\mathrm{km}^{2}$ da área urbana (MARINGÁ, 1997) estão ocupados por reservas/parques e tendo classificado $5,31 \mathrm{~km}^{2}$ de vegetação nativa em área urbana, conclui-se que as áreas de vegetação nativa disseminadas na área urbana chegam a 2,97 km² (2,33\%). Portanto, na área urbana, aproximadamente $50 \%$ da área de vegetação nativa estão em reservas/parques.

Considerando a mata nativa na área urbana e rural, tem-se um total de $19,36 \mathrm{~km}^{2}(3,95 \%)$ ocupado por essa categoria no município.

A cana-de-açúcar ocupa $8,18 \mathrm{~km}^{2}(1,67 \%)$ da área do município (Tabela 1). Pequenas áreas ocupadas por canaviais estão localizadas, geralmente, junto às áreas de pastagens. 
A capoeira ocupa a menor área $\left(3,27 \mathrm{~km}^{2}\right)$ do município (Tabela 1), ocorrendo predominantemente a sudoeste.

A carta de aptidão agrícola do município de Maringá pode ser visualizada na Figura 3, notandose que as áreas indicadas para lavouras ocorrem praticamente em todo o município.

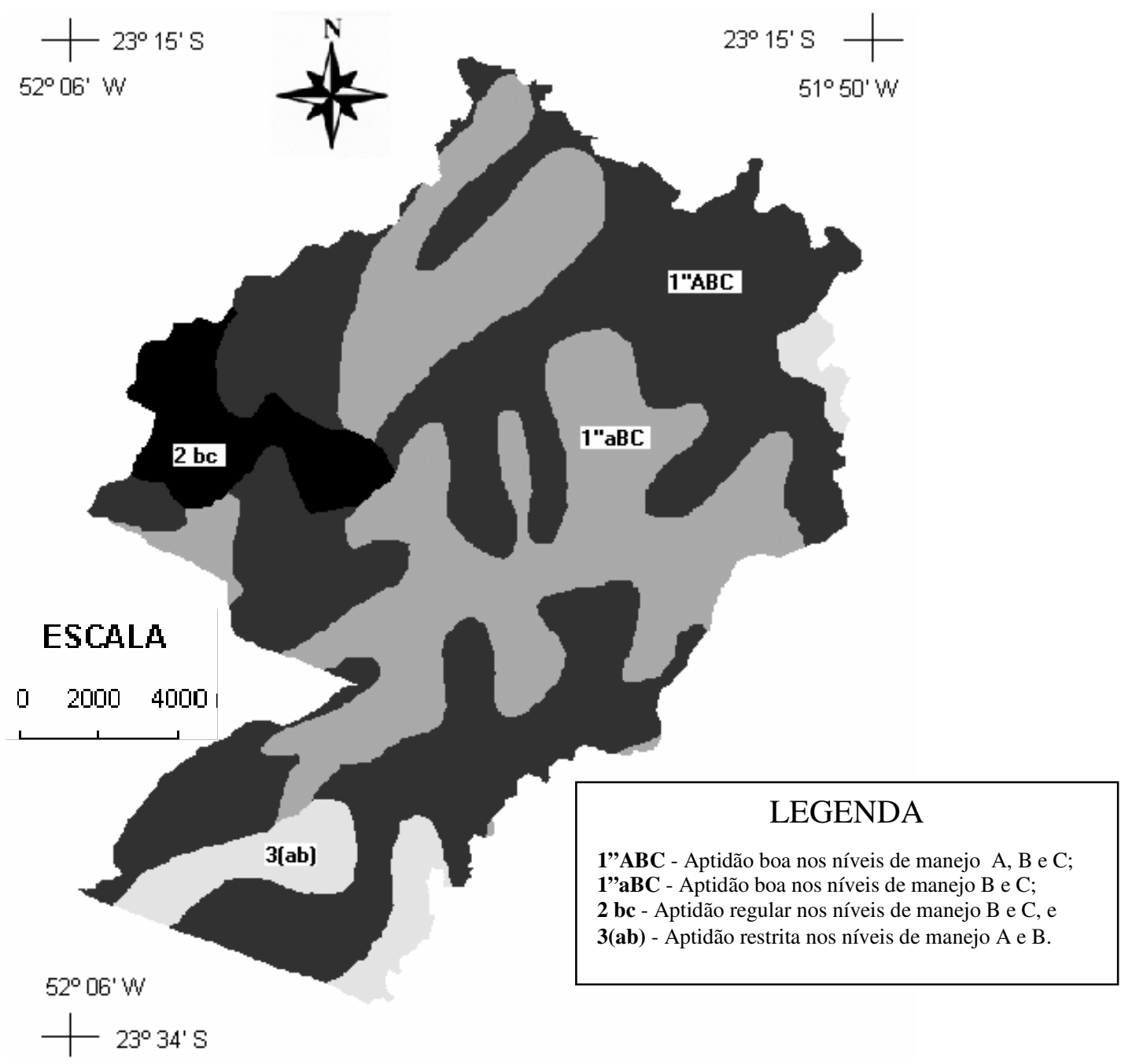

FIGURA 3. Carta de aptidão agrícola do município de Maringá - PR, obtida pelo sistema SITIM/INPE.

A Tabela 2, obtida por meio da Figura 3, apresenta a distribuição absoluta $\left(\mathrm{km}^{2}\right)$ e a porcentagem dos grupos de aptidão agrícola encontrados no município. A maior porção da área estudada $(87,47 \%)$ apresenta aptidão boa para lavouras (1'ABC e 1'aBC), com até dois cultivos por ano, em pelo menos dois níveis de manejo $\mathrm{A}, \mathrm{B}$ ou $\mathrm{C}$, ou seja, 33,80\% da área estudada, enquanto 53,67\% enquadram-se nos níveis médio a alto.

As áreas restantes $\left(61,38 \mathrm{~km}^{2}\right)$ apresentam aptidão regular $2 \mathrm{bc}\left(30,06 \mathrm{~km}^{2}\right)$, exigindo médios e altos níveis tecnológicos, e restritas $3(\mathrm{ab})\left(31,32 \mathrm{~km}^{2}\right)$ para lavouras.

A sobreposição, por meio do SGI, do mapa de aptidão agrícola (Figura 3) com o mapa de uso e ocupação do solo (Figura 2) permitiu a confecção da Tabela 3, que apresenta a distribuição absoluta $\left(\mathrm{km}^{2}\right)$ e porcentagens das áreas, segundo grupos de aptidão para cada uso e ocupação do solo. 
TABELA 2. Distribuição da área absoluta $\left(\mathrm{km}^{2}\right)$ e porcentagem $(\%)$, conforme grupos de aptidão agrícola no município de Maringá - PR.

Grupos de Aptidão Agrícola

Área

Grupo 1- Aptidão boa para lavouras, em pelo menos um dos

níveis de manejo, A, B ou C. Subgrupo: l'ABC Aptidão boa nos

níveis de manejo $A, B$ e $C$.

1 ”a BC Aptidão boa nos níveis de manejo B e C.

262,84

53,67

Grupo 2- Aptidão regular para lavouras, em pelo menos um dos

níveis de manejo, A, B ou C. Subgrupo: 2bc Aptidão regular nos

30,06

6,14

níveis de manejo $B$ e $C$.

Grupo 3- Aptidão restrita para lavouras, em pelo menos um dos

níveis de manejo, A, B ou C. Subgrupo: 3(ab) Aptidão restrita

nos níveis de manejo $A$ e $B$.

Total

31,32

6,39

489,76

100,00

Na Tabela 3, pode-se constatar que, da área ocupada por cultura, 89,42\% estão em condições de boa aptidão para lavoura $(29,98 \%$ em 1"aBC e 59,44\% em 1'ABC) e 7,33\% em condições de restrição à lavoura (3ab).

TABELA 3. Distribuição absoluta $\left(\mathrm{km}^{2}\right)$ e porcentagem (\%) das áreas segundo grupos de aptidão agrícola para cada tipo de uso e ocupação do solo, no município de Maringá - PR.

\begin{tabular}{|c|c|c|c|c|c|c|c|c|c|c|}
\hline \multirow{3}{*}{$\begin{array}{l}\text { Uso do } \\
\text { Solo }\end{array}$} & \multicolumn{10}{|c|}{ Grupo de Aptidão } \\
\hline & \multicolumn{2}{|c|}{$1 " a B C$} & \multicolumn{2}{|c|}{ 1'ABC } & \multicolumn{2}{|c|}{$2 b c$} & \multicolumn{2}{|c|}{$3(a b)$} & \multicolumn{2}{|c|}{ Total } \\
\hline & $\mathrm{km}^{2}$ & $(\%)$ & $\mathrm{km}^{2}$ & $(\%)$ & $\mathrm{km}^{2}$ & $(\%)$ & $\mathrm{km}^{2}$ & $(\%)$ & $\mathrm{km}^{2}$ & $(\%)$ \\
\hline Cultura & 57,19 & 29,98 & 113,38 & 59,44 & 6,19 & 3,24 & 13,99 & 7,33 & 190,75 & 100,00 \\
\hline Pastagem & 11,79 & 17,27 & 38,45 & 56,32 & 12,41 & 18,18 & 5,62 & 8,23 & 68,27 & 100,00 \\
\hline $\begin{array}{c}\text { Mata } \\
\text { nativa }\end{array}$ & 1,49 & 10,60 & 9,69 & 68,97 & 1,15 & 8,19 & 1,72 & 12,24 & 14,05 & 100,00 \\
\hline $\begin{array}{l}\text { Cana-de- } \\
\text { açúcar }\end{array}$ & 0,96 & 11,74 & 5,39 & 65,89 & 1,60 & 19,56 & 0,23 & 2,81 & 8,18 & 100,00 \\
\hline Capoeira & 0,69 & 21,10 & 1,40 & 42,82 & - & - & 1,18 & 36,08 & 3,27 & 100,00 \\
\hline Outros & 14,79 & 19,04 & 45,48 & 58,69 & 8,71 & 11,22 & 8,58 & 11,05 & 77,66 & 100,00 \\
\hline
\end{tabular}

Analisando a situação de Outros (múltiplos usos), na Tabela 3, nota-se que 77,66\% do total de sua área estão em terras de boa aptidão para lavoura (19,04\% em 1'aBC e 58,69\% em 1'ABC), enquanto $11,05 \%$ localizam-se em terras com restrição à lavoura (3ab).

Da área total ocupada por Pastagem, 73,59\% (Tabela 3) estão em terras de boa aptidão para lavoura (17,27\% em 1'aBC e 56,32\% em 1'ABC), enquanto 18,18\% estão em terras de regular aptidão e apenas $8,23 \%$ apresentam-se em terras com restrição à lavoura (3ab). A Mata Nativa, com $14,05 \mathrm{~km}^{2}$, representa apenas $12,24 \%$ de ocupação de terrenos com restrição à lavoura (3ab).

Dos $8,18 \mathrm{~km}^{2}$ ocupados pela Cana-de-Açúcar, 77,63\% estão assentados em terrenos com boa aptidão para lavoura $(11,74 \%$ em 1'aBC e $65,89 \%$ em 1'ABC) e $19,56 \%$ em terrenos com regular aptidão, sob manejo de médio a alto nível tecnológico, havendo ainda $2,81 \%$ em área com restrição à lavoura.

Da área ocupada por Capoeira $\left(3,27 \mathrm{~km}^{2}\right)$, verifica-se que $63,92 \%$ estão em terrenos de boa aptidão para lavoura e 36,08\% em áreas com restrição à lavoura. 
Finalmente, pode-se constatar, na Tabela 3, a ordem decrescente de porcentagem de ocupação em terrenos de restrita aptidão para lavoura: Capoeira (36,08\%), Mata Nativa (12,24\%), Outros $(11,05 \%)$, Pastagem (8,23\%), Cultura (7,33\%) e Cana-de-Açúcar $(2,81 \%)$.

As ocupações, em ordem decrescente, em terrenos de regular aptidão para lavoura usando níveis tecnológicos médios e altos, são: Cana-de-Açúcar (19,56\%), Pastagem (18,18\%), Outros (11,22\%), Mata Nativa (8,19\%), Cultura (3,24\%) e a não-ocorrência de Capoeira (Tabela 3).

As ocupações, em ordem decrescente de área total com lavoura, que ocorrem em terrenos com boa aptidão (Figura 3 e Tabela 3), são: Cultura (89,42\%), Mata Nativa (79,57\%), Outros (77,66\%), Cana-de-Açúcar (77,63\%), Pastagem (73,59\%) e Capoeira (63,92\%). A alta porcentagem da área de Mata Nativa (segunda classificada) em terrenos com boa aptidão para a lavoura deve estar vinculada à imposição da legislação ambiental.

\section{CONCLUSÕES}

Por meio da análise conjunta dos mapas de ocupação do solo com a carta de aptidão agrícola, constata-se que o município de Maringá - PR, apresenta ocupação de suas terras, em sua grande maioria, em acordo com a aptidão agrícola recomendada para a região, e a alta porcentagem de mata nativa em terras de boa aptidão para culturas, certamente, está vinculada à obediência às leis ambientais em vigor.

\section{REFERÊNCIAS BIBLIOGRÁFICAS}

ALVES, A.R.; LAPOLLI, E.M.; BASTOS, R.C.; BASTOS, L.C. Classificação de imagens digitais pelo método da máxima verossimilhança - uma nova abordagem. In: SIMPÓSIO BRASILEIRO DE SENSORIAMENTO REMOTO, 7., 1993, Curitiba. Anais... Curitiba: SBSR, 1993. p.281-3.

CRÓSTA, A.P. Processamento digital de imagens de sensoriamento remoto. Campinas: Instituto de Geociências, UNICAMP, 1992. 170 p.

EMBRAPA. SNLCS. Levantamento de reconhecimento dos solos do Estado do Paraná. Curitiba, 1984. 791 p. (Boletim Técnico, 57).

ENGESPAÇO. Manual do usuário: SITIM 340/SGI. São José dos Campos: INPE, 1989.

GOES, M.H.B. Diagnóstico ambiental por geoprocessamento do município de Itaguaí (RJ). 1994. 529 f. Tese (Doutorado em Geociências e Meio Ambiente) - Instituto de Geociências, Universidade Estadual Paulista, Rio Claro, 1994.

LAPOLLI, E.M.; ALVES, A.R.; BARCIA, R.M. Classificação de imagens digitais: comparação entre vários métodos. In: SIMPÓSIO BRASILEIRO DE SENSORIAMENTO REMOTO, 7., 1993, Curitiba. Anais... Curitiba: SBSR, 1993. p.373-80.

MAGUIRE, D.; GOODCHILD, M.F.; RHIND, D. (Ed). Geographical Information Systems Applications. 2.ed. London: Longman Scientific \& Technical, 1991. v.2, 447 p.

MARINGÁ. Prefeitura Municipal. Secretaria de Planejamento. Divisão de modernização Administrativa e Controle de Qualidade. Perfil da Cidade de Maringá. Maringá, 1997. 259 p.

QUEIRÓZ, E.F.; TORRES, E. Cultura da soja - parâmetros ambientais e épocas de semeadura. In: MANUAL agropecuário para o Paraná. Londrina: Fundação Instituto Agronômico do Paraná, 1978. p.353-6.

RAMALHO FILHO, A.; BEEK, K.J. Sistema de avaliação da aptidão agrícola das terras. 3.ed. Rio de Janeiro: EMBRAPA-CNPS, 1994. 313 p.

SERRA, G. O espaço natural e a forma urbana. São Paulo: Nobel, 1987. 211 p. 